\title{
Systematic study of graphite encapsulated nickel nanocrystal synthesis with formation mechanism implications
}

\author{
Jonathon J. Host and Vinayak P. Dravid ${ }^{\text {a) }}$ \\ Department of Materials Science and Engineering \& Materials Research Center, Northwestern \\ University, Evanston, Illinois 60208 \\ Mao-Hua Teng \\ Department of Geology, National Taiwan University, 245 Chou-Shan Road, Taipei, Taiwan, Republic \\ of China
}

(Received 10 January 1997; accepted 2 September 1997)

By systematically varying the carbon content, chamber pressure, arc current, and blowing gas velocity in a tungsten-arc encapsulation setup, the effects of each of these variables on the encapsulation of nickel in graphite layers were observed. The data from these optimally designed experiments revealed that the properties of the arc translate into changes in the encapsulated product. Specifically, a larger, hotter arc results in more encapsulation in the final sample. These findings, along with evidence of graphite layers which have formed on precrystallized particles, indicate that the graphite layers may form by two sequential formation steps. The first step is the simple phase segregation of carbon from a cooling liquid particle, resulting in surface graphite. The second step is the growth of carbon on a crystallized nickel particle, regardless of the temperature at which this occurs. The proposed formation mechanism has significant implications for both a scientific understanding of the encapsulation phenomena, and possible commercial applications.

\section{INTRODUCTION}

Graphite encapsulated magnetic nanocrystals ${ }^{1,2}$ are expected to have interesting properties and commercially valuable applications, ranging from magnetic data storage and ferrofluids to biomedical applications ${ }^{3}$, due to their magnetic properties ${ }^{4}$ and immunity to most environments as a result of the protective graphite coating. ${ }^{5}$ Graphite encapsulated metal nanocrystals of $\mathrm{Fe},{ }^{6} \mathrm{Co},{ }^{7}$ $\mathrm{Ni},{ }^{8} \mathrm{Cu},{ }^{9} \mathrm{Sm}-\mathrm{Co},{ }^{10}$ and $\mathrm{FeNdB}^{11}$ have been produced in small quantities, but because the basic encapsulation process is not well understood, improvements in the amount produced and the quality of the product have been rare. Direct observation of the encapsulation mechanism has proven difficult due to the small size of the nanocrystals, and the fact that the normal production of these materials occurs in the aggressive environment of an electric arc. This has resulted in uncertainty concerning the encapsulation process.

The lack of information on the encapsulation mechanism has slowed process optimization for the large scale production of these materials. To alleviate this problem and satisfy scientific curiosity, possible formation mechanisms have been proposed by various authors. These include a catalytic mechanism, ${ }^{12}$ a surface segregation mechanism, ${ }^{12}$ the two-step mechanism, ${ }^{13,14}$ and others.

\footnotetext{
a)Address correspondence to this author.
}

Though the formation mechanism has been the subject of significant speculation, ${ }^{12,15-25}$ few quantitative studies have been done. To remedy this problem, we have conducted a controlled study of the effects of varying the chamber pressure, arc current, arc carbon content, and gas blowing speed on the final encapsulated product. By changing these variables simultaneously, we have been able to observe the independent effects of each variable, elucidating the formation mechanism for these particles and improving the production rate and quality of the resulting product.

\section{EXPERIMENTAL}

The encapsulated particles were synthesized using the modified tungsten arc method, described in detail elsewhere. ${ }^{26}$ In short, vertical electrodes were used to strike an arc in an atmosphere of helium. The cathode was a tungsten rod $4.8 \mathrm{~mm}$ in diameter, while the anode was a $50 \mathrm{~mm}$ diameter composite crucible. Carbon was supplied by predissolving a known amount of carbon in the metal of the crucible. This carbon dissolution was done separately in an arc melter, allowing large amounts of carbon to be dissolved in liquid nickel. In this way, a consistent carbon supply was used, and sample variability was reduced. By maintaining the arc over the liquid metal pool for an hour per experiment, batches of particles ranging from less than $100 \mathrm{mg}$ to over a gram 
were produced. The modified tungsten arc method was used for this study to allow the independent variables to be adjusted.

Several variables needed to be included to get a complete view of the possible factors affecting the final product in the encapsulation process. These variables and the values used for each are shown in Table I.

Prior to our experiments, encapsulation was accomplished using a modified Krätschmer-Huffman method, ${ }^{27}$ yielding a very high carbon content. The graphite crucible used in our preliminary encapsulation experiments $^{28}$ was a step in the right direction by allowing some control of the carbon content, thus allowing the majority of the product to be metal particles, as opposed to carbonaceous debris. However, the carbon content was only partially controlled, being a function of the interfacial area between the metal and the graphite, the temperature of the crucible, the size of the metal pool, and the melt history of the pool. ${ }^{13}$ Because of this, the carbon content could still be very high, and would increase during the course of the experiment. To control the carbon content, a new crucible was designed with a predetermined amount of carbon dispersed in the nickel pool. This carbon forms a cast-iron microstructure on solidification, and redissolves when the nickel in the anode is melted by the arc. Carbon contents of only 2 and $8 \mathrm{wt}$ \% were chosen because very little carbon is needed to encapsulate the metal particles, as can be seen from Fig. 5 in Ref. 13.

Previous work both here at Northwestern and at other research facilities has shown the importance of the chamber pressure. ${ }^{24,26,28-30}$ The pressure in the arc chamber can affect the form that the carbon takes, resulting in nanotube formation at higher chamber pressures (>300 Torr) and buckyball formation at lower chamber pressures $(\approx 100$ Torr $) .{ }^{17}$ For this reason, it was believed that the chamber pressure may have an effect on the encapsulation process. Chamber pressures of 100 and 400 Torr were used to represent both a high and a low chamber pressure.

Increasing the current of the arc leads to a higher production rate, so low arc currents were avoided. However, increasing the arc current thermally endangers both the chamber and the crucible. To balance these two effects, arc currents of 80 and 120 A were used. Because the arc voltage is kept near $20 \mathrm{~V}$, the arc current was directly related to the overall power.

The blowing speed of the quenching gas jet was shown previously to reduce the size of the unencapsulated particles ${ }^{28}$ so the effect of the blowing speed on the average size and size distribution of the encapsulated particles was of interest. The blowing speed was also selected for study because it may affect the cooling rate of the individual particles. The values of 10 and $40 \mathrm{~m} / \mathrm{s}$ were used such that the high value $(40 \mathrm{~m} / \mathrm{s})$ was well above that needed to cause a reduction in unencapsulated particle size. ${ }^{28}$

Because of the volatility of the arc process, each experimental condition used was tested twice to reduce experimental variability. Fourteen experiments (shown in Table I) were selected from the full factorial matrix using the EXPERIMENTAL DESIGN OPTIMIZER software. ${ }^{31}$

After removing the particles (some of which were unencapsulated) from the walls of the chamber, they were immersed in $\mathrm{HNO}_{3}$ in an ultrasonic bath for $2 \mathrm{~min}$, dissolving unprotected nanocrystals. The particles were pulled to the wall of the beaker by the application of a magnetic field while the acid solution was replaced with water, and finally with methanol. A pipette was used to transfer the resulting particle suspension to a TEM grid.

The output from each experiment was weighed (both before and after the acid wash) and analyzed by several techniques. The general morphology, average particle size, and particle size distribution were measured by conventional TEM, while the crystallinity of the carbon present and the amount of carbonaceous debris were measured by HREM, avoiding areas with severe agglomeration. The weight of the carbonaceous debris was estimated using the densities of carbon and nickel, and the weight of encapsulated material was estimated by subtracting the debris weight from the total weight. The average particle size was recorded by measuring 100 particles on a TEM micrograph of the sample in question. Phase analysis was done using both $\mathrm{x}$-ray diffraction and electron nanodiffraction. Local and overall chemistry was measured using energy dispersive

TABLE I. Experimental conditions used in this study. Each experiment was done twice to reduce experimental variability. This set of experiments was determined by the EXPERIMENTAL DESIGN OPTIMIZER software to maximize the amount of information gained in seven experiments.

\begin{tabular}{ccccc}
\hline \hline Experimental condition no. & Carbon content wt. \% & Chamber pres. (Torr) & Arc current (amps) & Blowing velocity (m/s) \\
\hline 1 & 8 & 400 & 120 & 120 \\
2 & 2 & 400 & 120 & 40 \\
3 & 8 & 100 & 80 & 40 \\
4 & 2 & 100 & 120 & 10 \\
6 & 2 & 100 & 80 & 10 \\
7 & 8 & 100 & 80 & 10 \\
\hline \hline
\end{tabular}


spectrometry. X-ray diffraction (XRD) experiments were conducted using $\mathrm{CuK}_{\alpha}$ radiation in a Scintag X-ray diffractometer. Conventional TEM (for determining the average size and general morphology), electron nanodiffraction (to locally confirm the XRD phase analysis), and HREM were done using a Hitachi HF-2000 cold field emission analytical transmission electron microscope. Energy dispersive spectrometry (EDS) was also carried out with this microscope, which is equipped with an Oxford Pentafet ultrathin window x-ray detector.

\section{RESULTS}

Observations of the samples using the techniques mentioned above gave a good understanding of both the overall and microscopic properties of each sample. Because of the more efficient cooling of the water-cooled crucible, the melt pool stayed at a lower temperature than when a graphite crucible (which has an uncontrolled carbon content) was used. After the acid wash, all of the samples were composed of face-centered cubic (fcc) nickel particles with a graphite coating, along with carbonaceous debris. Nickel particles coated only with an amorphous carbon coating were rare, and no carbide phase was detected. There was no evidence for significant amounts of carbon retained in solid solution, which is consistent with the fact that only a short time is needed for diffusion from small particles such as these. For example, calculations show that only $20 \mathrm{~ms}$ are needed for $95 \%$ of the carbon present in a nickel nanoparticle $10 \mathrm{~nm}$ in diameter to diffuse out. This is discussed in detail on pages 55 and 56 of Ref. 14.

Generally, the number of graphite layers was positively correlated with the nanocrystal size in a given sample, as shown in Fig. 1. This general correlation between the nanocrystal size and the number of graphite layers is in agreement with a similar finding reported by Seraphin for $\mathrm{YC}_{2}{ }^{24,32}$ nanocrystals. There were significant deviations from this rule, however, which may have been caused by further coating after solidification, or by variations in initial particle carbon content.

Data gained on the weight of particles produced, the weight encapsulated, the average particle size and particle size distribution, along with the estimated weight of carbonaceous debris produced and the crystallinity of the carbon were analyzed using the MULTIPLE CORRELATION ${ }^{31}$ software. The MULTIPLE CORRELATION software fits a response to the independent variable in question using linear regression. Results of each experiment are tabulated in Table II. Coded variables are used to compute the expected output based on each of the coefficients given in the table following each plot. The coded variable can be computed from the actual value of a variable in any experiment by the following formula:

$$
V=(N-M) /(D / 2),
$$

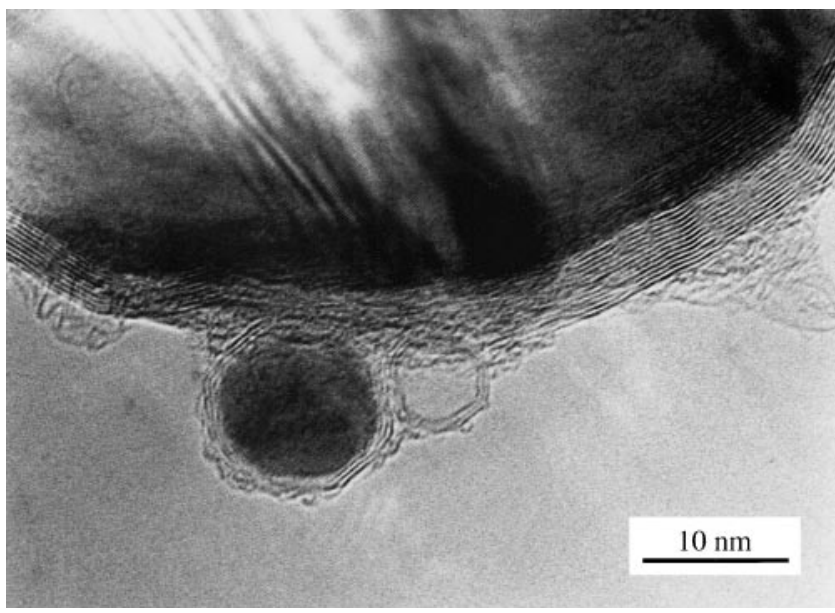

FIG. 1. HREM image of nickel nanocrystals showing relation between particle size and the number of graphite layers. Though exceptions can be found, large particles in a given sample are coated with more layers than smaller particles. This is expected, assuming that some of the encapsulation is the result of carbon segregation.

where $V=$ the coded variable, $N=$ the value of the original independent variable, $M=$ the value of the midpoint of the independent variable in this experimental set, and $D=$ the difference between the maximum and minimum values taken by the variable in question.

By applying Eq. (1) to the values in Table I, the coded variable for the experimental set can be computed. These values vary between -1 and 1 , where -1 represents the lowest value the variable attains, and 1 represents the highest value the variable attains.

The predicted value for each of the dependent variables can be calculated from the coded variables by multiplying each coefficient with the value of the coded variable, and adding the intercept value. Because several variables are being tested in each experiment, the results of each experiment cannot be shown on the response surfaces found by linear regression of the results. The accuracy of each of the response surfaces is shown graphically in Ref. 14. Through the precision of the various measurement techniques varies, some clear trends were seen.

\section{A. Raw (unwashed) sample weight}

The raw production was found to be strongly affected by the arc current. This was not surprising, since it simply confirmed a result found earlier. ${ }^{33}$ However, it was found that the carbon content affected the total raw production rate nearly as much (Fig. 2), indicating that the thermal conductivity of the melt pool (which affects the temperature of the melt pool) was important as well. An interaction between the chamber pressure and the blowing velocity also affected the raw production. The coefficients used to generate Fig. 2 are listed in Table III. Only the vaporization of material from the 
TABLE II. Raw data from the experimental set in Table I. Analysis using linear regression resulted in Figs. 2-5.

\begin{tabular}{|c|c|c|c|c|c|c|}
\hline Condition no. & $\begin{array}{c}\text { Total } \\
\text { powder }(\mathrm{mg})\end{array}$ & $\begin{array}{c}\text { Encap. } \\
\text { particles (mg) }\end{array}$ & $\begin{array}{l}\text { Estimated } \\
\text { debris (mg) }\end{array}$ & $\begin{array}{l}\text { Average } \\
\text { size }(\mathrm{nm})\end{array}$ & $\begin{array}{l}\text { St. dev. of } \\
\text { size }(\mathrm{nm})\end{array}$ & $\begin{array}{c}\text { Carbon } \\
\text { crystallinity }(\%)\end{array}$ \\
\hline 1 & 1214 & 0 & 0 & 9.9 & 11 & 40 \\
\hline 1 & 1227 & 0 & 0 & 17 & 9 & 30 \\
\hline 2 & 800.7 & 0 & 0 & $\cdots$ & $\cdots$ & $\cdots$ \\
\hline 2 & 824.1 & 0 & 0 & 12 & 10 & 40 \\
\hline 3 & 881.4 & 21 & 8 & 11 & 7 & 70 \\
\hline 3 & 426.0 & 20 & 7 & 13 & 10 & 80 \\
\hline 4 & 234.8 & 6 & 2 & 19 & 13 & 40 \\
\hline 4 & 78.1 & 7 & 2 & 11 & 6 & 60 \\
\hline 5 & 833.5 & 15 & 4 & 16 & 12 & 90 \\
\hline 5 & 647.1 & 19 & 5 & 12 & 7 & 70 \\
\hline 6 & 995.0 & 20 & 7 & 13 & 10 & 70 \\
\hline 6 & 943.4 & 38 & 10 & 16 & 11 & 70 \\
\hline 7 & 653.1 & 40 & 8 & 16 & 13 & 30 \\
\hline 7 & 477.0 & 6 & 2 & 11 & 6 & 30 \\
\hline
\end{tabular}

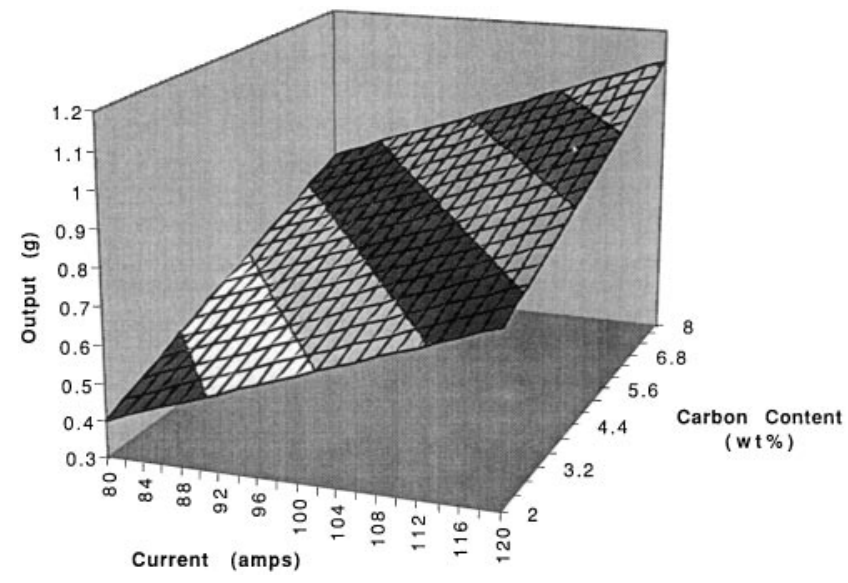

FIG. 2. Total production was found to be a function of the arc current, carbon content, and an interaction between the chamber pressure and the blowing velocity. For this plot, both the chamber pressure and the blowing velocity are set at their median values. The arc current and the carbon content control the temperature at the surface of the pool, where evaporation takes place, thus controlling the raw production.

TABLE III. Variables affecting the total production rate. The $T$ values and $R$ squared values describe the error in each variable. The overall $R$ squared value for this correlation set was $98.6 \%$.

\begin{tabular}{lccc}
\hline \hline \multicolumn{1}{c}{ Variable } & $\begin{array}{c}\text { Coefficient } \\
(\mathrm{mg})\end{array}$ & $T$ value & $\begin{array}{c}R \text { squared } \\
\text { value }\end{array}$ \\
\hline Intercept & 658 & $\ldots$ & $\ldots$ \\
Carbon in crucible (wt. \%) & 194 & 8.82 & 0.04 \\
Arc current & 80 & 3.35 & 0.18 \\
Pressure blowing velocity & 238 & 9.95 & 0.18 \\
\hline \hline
\end{tabular}

pool need be considered here, since the total production measured the weight of all of the material collected from the chamber, regardless of particle size, encapsulation, debris production, etc.

To illustrate the use of the linear regression data, the coefficients shown in Table III can be used to compute the predicted output of a given experiment by using the coded variables for that experiment and the following formula:

$$
\begin{array}{r}
I+C_{1} \times V_{1}+C_{2} \times V_{2}+\cdots+C_{i} \times \\
V_{i}+\cdots=P,
\end{array}
$$

where $I=$ the intercept value, $C_{i}=$ the coefficient for parameter $i, V_{i}=$ the value of the coded variable for the parameter $i$, and $P=$ the predicted output of the experiment.

For example, predicting the total powder production using Eq. (2) for experimental condition no. 1 in Table I and the coefficients for the total powder production in Table III gives the following:

$$
\begin{array}{r}
658+194 \times(1)+80 \times(1)+238 \times(1) \\
=1170 \mathrm{mg},
\end{array}
$$

where $1170 \mathrm{mg}$ is predicted by the model, while $1214 \mathrm{mg}$ (Table II) was produced by these experimental conditions.

\section{B. Encapsulated weight}

The encapsulated weight was found by subtracting the estimated debris weight from the weight of the particles that survived the acid treatment. Though the data for the amount of encapsulated product contains more scatter than the total production, some trends were visible. The weight of encapsulated particles was found to be decreased by either an increase in the chamber pressure or the blowing velocity, as is shown in Fig. 3. An increase in the chamber pressure resulted in a smaller arc (perhaps by increasing the density of charge carriers), decreasing the time in which the particle was exposed to the conditions near the arc. A higher blowing speed also resulted in a shorter time near the arc, and a faster dispersion of the different constituents of the 


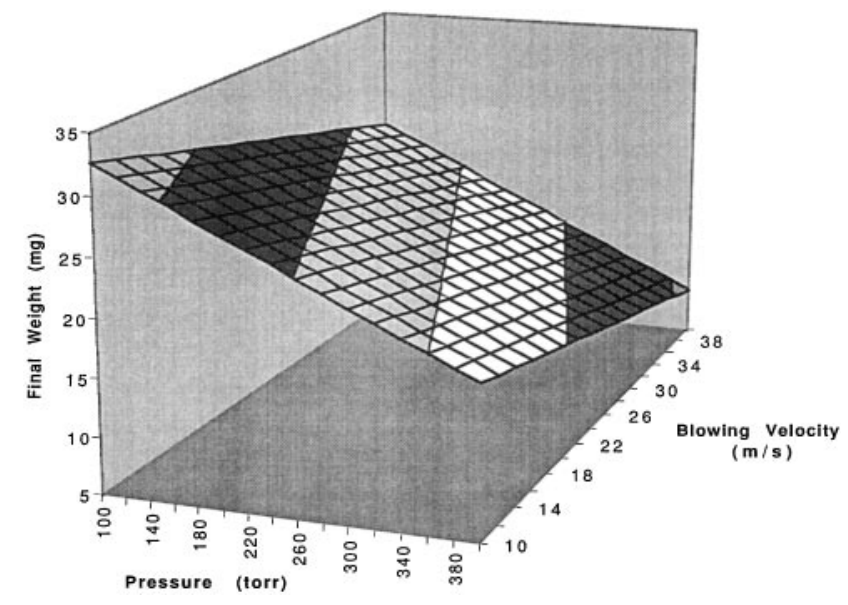

FIG. 3. The weight of encapsulated particles was affected by the carbon content, chamber pressure, and the blowing gas speed. This was expected due to the post-solidification encapsulation which occurs near the arc.

vapor. The last independent variable that was found to affect the amount of final encapsulated particles was, not surprisingly, the carbon content. A higher carbon content resulted in a larger production of encapsulated particles. However, this effect was smaller than either the effect of the chamber pressure or the blowing speed. In fact, some experiments at a high blowing speed and a high chamber pressure had almost no encapsulated product at all, even at a high carbon content. The coefficients controlling the weight of encapsulated particles are shown in Table IV.

\section{Average particle size and distribution}

No correlations were found between any of the independent variables and the average encapsulated particle size or encapsulated particle size distribution. This finding is not necessarily in conflict with an earlier correlation between the blowing speed and the average particle size for unencapsulated particles,$^{28}$ because the encapsulation may affect the agglomeration and growth of these particles.

\section{Production of carbonaceous debris}

The area fraction of carbonaceous debris was measured by TEM (avoiding areas where the particle number

TABLE IV. Variables affecting the encapsulated production rate. The overall $R$ squared value for this correlation set was $88.3 \%$.

\begin{tabular}{lrcc}
\hline \hline \multicolumn{1}{c}{ Variable } & $\begin{array}{c}\text { Coefficient } \\
(\mathrm{mg})\end{array}$ & $T$ value & $\begin{array}{c}R \text { squared } \\
\text { value }\end{array}$ \\
\hline Intercept & 13.2 & $\ldots$ & $\ldots$ \\
Carbon in crucible (wt. \%) & 4.8 & 2.2 & 0.07 \\
Chamber pressure & -4.9 & -2.24 & 0.07 \\
Gas jet velocity & -6.4 & -2.93 & 0.07 \\
\hline \hline
\end{tabular}

density was too high to distinguish carbonaceous debris), and then this area fraction was converted to a weight using the densities of carbon and nickel. Also, thick layers of graphite can easily be confused with graphitic debris. Because of these problems, the weight of the carbonaceous debris is only accurate to one significant figure. In all experiments, much of the debris was found to be composed of graphene layers. Using the graphite crucible (which allowed a higher melt pool temperature but lacked control over the carbon content) resulted in some experiments with reduced carbonaceous debris, suggesting that the temperature of the melt pool may affect the production of debris. However, the strong and uncontrolled effect of the varying carbon content prevented the use of the graphite crucible in this study.

The weight of carbonaceous debris was controlled by the chamber pressure, the blowing velocity, and the carbon content (Fig. 4). The coefficients giving the predicted carbonaceous debris production are shown in Table V. Because the encapsulated production and the production of carbonaceous debris are controlled by the same factors, there is only a small variation in the fraction of a given sample which is composed of carbonaceous debris.

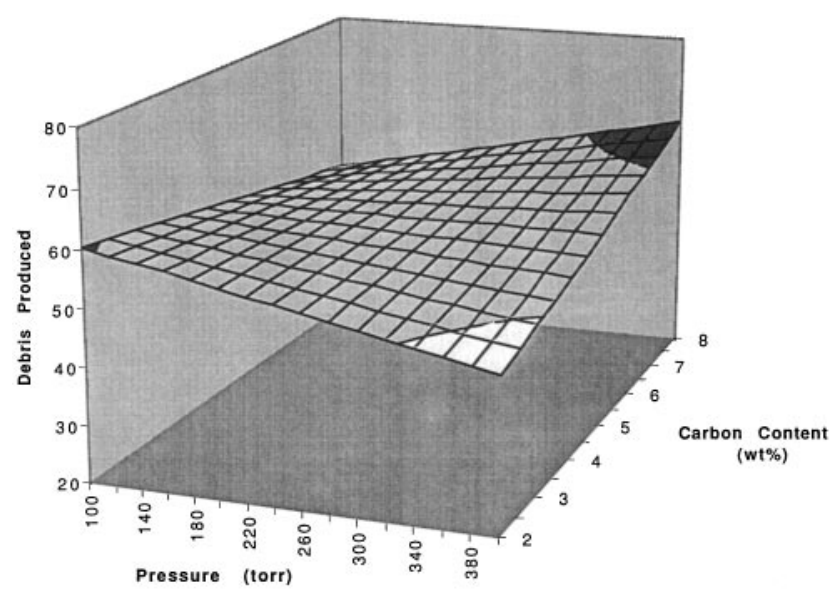

FIG. 4. The amount of carbonaceous debris produced was strongly affected by the same factors that controlled the production of encapsulated materials. This may have been partly due to the fact that partially encapsulated particles are not protected from the acid, and therefore contribute to the debris.

TABLE V. Variables affecting the production rate of the carbonaceous debris. The overall $R$ squared value for this correlation set was $88.1 \%$.

\begin{tabular}{lccc}
\hline \hline \multicolumn{1}{c}{ Variable } & $\begin{array}{c}\text { Coefficient } \\
(\mathrm{mg})\end{array}$ & $T$ value & $\begin{array}{c}R \text { squared } \\
\text { value }\end{array}$ \\
\hline Intercept & 3.7 & $\ldots$ & $\ldots$ \\
Carbon in crucible (wt. \%) & 1.7 & 2.52 & 0.07 \\
Chamber pressure & -2.8 & -3.03 & 0.07 \\
Gas jet velocity & -1.4 & -2.01 & 0.07 \\
\hline \hline
\end{tabular}




\section{E. Carbon crystallinity}

The crystallinity of the carbon was also measured by TEM. Because of the imaging characteristics of graphite, only graphite with its $c$-axis located approximately perpendicular to the electron beam was revealed to be crystalline, which made the sample appear less crystalline than it really was. However, graphite with its $c$-axis perpendicular to the electron beam results in a high contrast image, so a small amount of graphite with the right orientation was recorded as crystalline even if it was superimposed on a thicker amorphous region, which made the sample appear more crystalline than it really was. Because of these conflicting effects, the crystallinity data are accurate only to one significant figure. Significant variations in the crystallinity were observed (as can be seen in Table II, Fig. 5), but these did not correlate with any of the independent variables.

\section{DISCUSSION}

The results of this study point toward a formation mechanism. The results discussed above are explained within the framework of this proposed formation mechanism in Table VI, while the resulting formation of the encapsulated nanocrystals is illustrated in Fig. 6. The data show that some factors do favor encapsulation, but it should be emphasized that the possible formation implications discussed here are speculative. Furthermore, though only nickel metal was used in this study, it is suspected that several other metals ${ }^{14}$ may encapsulate by a similar process.

The proposed mechanism can be best understood by proceeding along the numbered path in Fig. 7. Both the nickel and the carbon begin the process in the single phase (carbon dissolved in liquid nickel) melt pool below

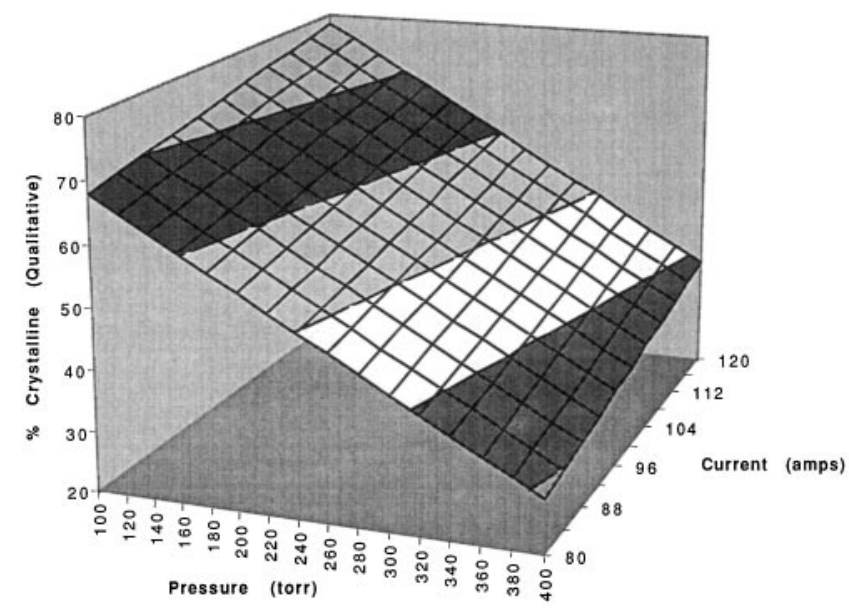

FIG. 5. Crystallinity of graphite is positively correlated with reduction in chamber pressure and increase in arc current. However, there is a considerable ambiguity with respect to identification of crystallinity (see text).

the arc (location 1 in Fig. 7). Nickel and carbon are coevaporated from the pool by the arc (2). Because the ratio of the vapor pressure of carbon to that of nickel between 1000 and $2000{ }^{\circ} \mathrm{C}$ is only about $1: 100,000,{ }^{35}$ the dynamic process of arc evaporation is needed to vaporize significant quantities of carbon. Because of the high temperature of the arc, nickel remains completely vaporized $^{34}$ while in the arc (3). As the material is swept out of the arc by thermophoresis and strong convection forces, small particles containing nickel and carbon begin to condense (4). Because of variations in carbon concentration, some particles have sufficient carbon to form graphite layers, while others contain little carbon. Homogeneous carbon nucleation also occurs to a limited extent, forming some carbonaceous debris. At this stage

TABLE VI. A brief summary of the major findings. This can be compared to the experimental results in Figs. 2-5. Positive correlations are denoted by $(+)$, negative correlations are denoted by $(-)$, and a lack of correlation is denoted by ( ). A possible explanation follows each correlation. Lastly, the relevant steps in Figs. 6 and 7 is listed.

\begin{tabular}{|c|c|c|c|c|}
\hline Experimental result & $\begin{array}{l}\text { Effect of carbon } \\
\text { content on: }\end{array}$ & $\begin{array}{l}\text { Effect of } \\
\text { pressure on: }\end{array}$ & $\begin{array}{l}\text { Effect of arc } \\
\text { current on: }\end{array}$ & $\begin{array}{l}\text { Effect of blow } \\
\text { speed on: }\end{array}$ \\
\hline \multirow{2}{*}{$\begin{array}{l}\text { Total weight of powder } \\
\text { produced }\end{array}$} & $(+)$ & ( ) & $(+)$ & ( ) \\
\hline & $\begin{array}{l}\text { A lower melt pool thermal } \\
\text { conductivity results in a } \\
\text { higher pool surface } \\
\text { temperature. Step } 2\end{array}$ & Step 2 & $\begin{array}{l}\text { A higher current (power) } \\
\text { yields a higher pool } \\
\text { surface temperature. } \\
\text { Step } 2\end{array}$ & Step 2 \\
\hline \multirow{2}{*}{$\begin{array}{l}\text { Weight of encapsulated } \\
\text { particles }\end{array}$} & $(+)$ & $(-)$ & ( ) & $(-)$ \\
\hline & $\begin{array}{l}\text { More carbon for encapsulation. } \\
\text { Steps } 4 \text { and } 6\end{array}$ & $\begin{array}{l}\text { Reduced arc size. } \\
\quad \text { Step } 6\end{array}$ & Steps 4 and 6 & $\begin{array}{l}\text { Removal from the arc } \\
\text { vicinity. Step } 6\end{array}$ \\
\hline \multirow{2}{*}{$\begin{array}{l}\text { Weight of carbonaceous } \\
\text { debris }\end{array}$} & $(+)$ & $(-)$ & ( ) & $(-)$ \\
\hline & $\begin{array}{l}\text { More carbon for debris } \\
\text { formation. Steps } 4 \text { and } 6\end{array}$ & $\begin{array}{l}\text { Reduced arc size. } \\
\text { Step } 6 .\end{array}$ & Steps 4 and 6 & $\begin{array}{l}\text { Removal from the arc } \\
\text { vicinity. Step } 6\end{array}$ \\
\hline
\end{tabular}




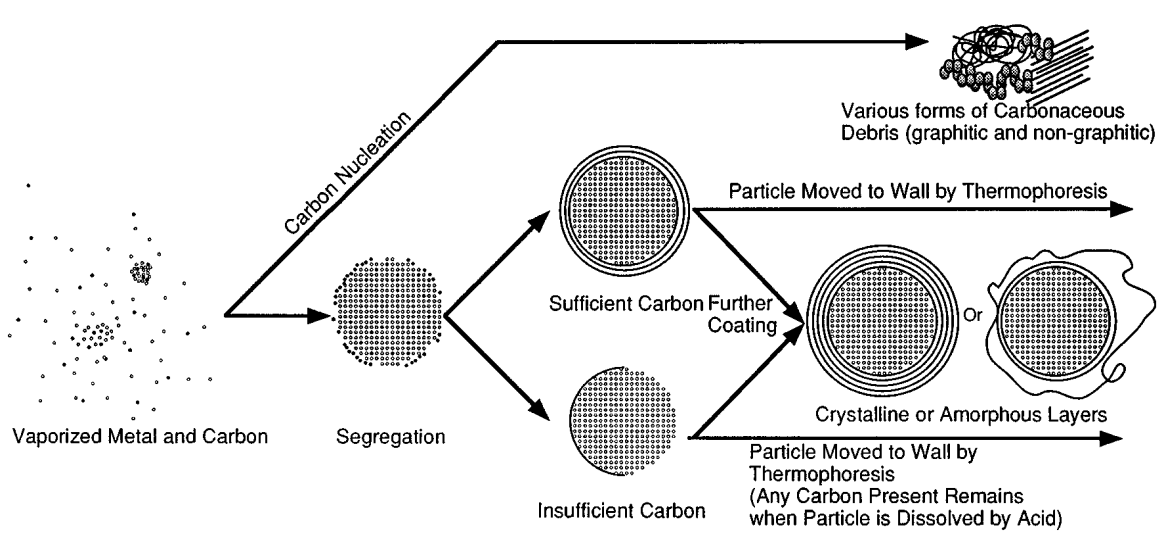

FIG. 6. Formation path of nickel nanocrystals in this study. Encapsulation can occur by two mechanisms. One mechanism is the segregation of carbon to the surface of the particle, and the other is the coating of a solid particle with graphite layers.

some layers of graphite form by the segregation of carbon from liquid particles of nickel-carbon solution. $24,32,35$ The particles are then swept from the arc vicinity by thermophoresis, convection, and the jet of blowing gas. Further cooling helps to force more carbon from the particles, perhaps forming layers on some bare particles, and additional layers on already coated particles (5). Many of the particles collect on the walls at this point, but those that do not are carried back near the arc by convection. Uncoated particles exposed to sufficient additional carbon may then gain a graphite coating. Reexposure of some of the carbon coated particles to the conditions near the arc could serve both to add additional carbon, and to graphitize ${ }^{36}$ amorphous coatings (6). The question of why structures containing alternating layers of graphite and nickel are not formed at this step may be answered by the vapor pressure difference. Because the vapor pressure of nickel is about 100,000 times that of graphite between $1000{ }^{\circ} \mathrm{C}$ and $2000{ }^{\circ} \mathrm{C}$, additional nickel remains gaseous at this point. Step 6 explains many of the trends seen in the experimental set, as shown in Table VI. Further evidence for this step is seen in Fig. 8, which shows partially sintered particles encapsulated by mutual graphite layers. If the graphite layers are formed only by segregation of the carbon above the eutectic temperature, then the particle would still be liquid when the graphite formed, and a spherical particle would result. ${ }^{37}$ This sintered morphology was rare, only three sintered pairs were observed in nearly four years of research. Though most of the particles were grouped in agglomerates, the amount of agglomeration could be reduced by using a more dilute ultrasonic dispersion.

The fact that at least some of the particles gain some or all of their graphite layers by subsequent coating after crystallizing is also shown by the presence of faceted particles. An encapsulated, faceted particle can be seen in Fig. 29 from Ref. 14. This particle probably gained its graphite layers after crystallizing to maintain a faceted shape, with additional carbon coating the particle from

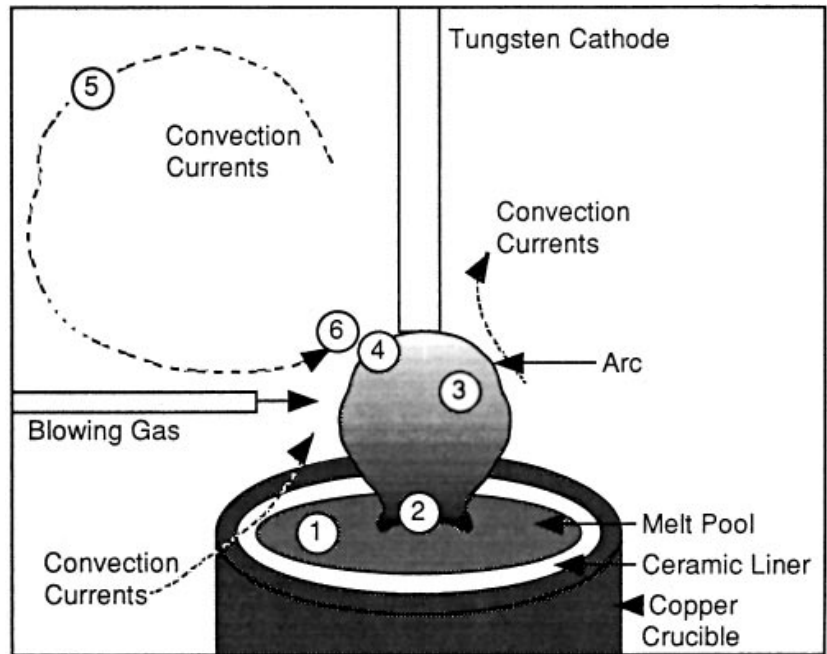

FIG. 7. Formation of encapsulated particles in the arc. The material starts in the single phase melt pool (1), is vaporized by the arc (2, 3 ), and then leaves the arc due to gas motion and thermophoresis (4). Subsequently, particles can be re-exposed to the arc conditions by convection $(5,6)$.

the gas after the initial layers formed. Simple segregation of carbon from a solid, faceted particle cannot explain this thick a coating, since the layers require about 40 wt. \% carbon, well above the solid solubility of carbon in nickel. This faceting may have a different cause than the faceting commonly observed along with open spaces in particles from cathode deposits. These facets may form during exposure to high temperatures, allowing the graphite to facet and core material to diffuse out from the particles (forming the open space). This process is described in detail in Ref. 14. The mechanism described above both explains the range of morphologies seen in nickel particles, as well as explaining the effects of each of the independent variables observed in this study.

Some correlations were expected but not seen. For instance, a higher arc current was expected to increase 
the amount of encapsulated product by allowing more efficient annealing of the carbon. This effect was not seen, probably due also to the small range of values for the arc current used (only 80 and 120 A). One experiment (outside the experimental set) was conducted using a higher arc current (150 A), and this experiment did produce more encapsulated material. Arc currents at or above $150 \mathrm{~A}$ could not be used regularly due to damage to the heat sensitive components of the encapsulation apparatus.

The elucidation of the two step segregation/coating encapsulation mechanism which appears to be occurring is consistent with the phase diagram for the nickelcarbon system. The two-step segregation/coating encapsulation mechanism has been applied to many other metal-carbon system phase diagrams as well, yielding significant agreement with experimental encapsulation results. ${ }^{14}$ This solves several problems in the encapsulation field. It explains the variation in the encapsulated material produced as a function of the parameters of the arc, improving scientific understanding of the formation of both the encapsulated particles and the other materials produced in the arc. Also, by optimizing the production of encapsulated particles, it potentially allows this process to be scaled up to an industrial level by further manipulation of the adjustable parameters. By using correlations learned in this study, further experiments were done using cobalt and nickel, resulting in successful production of larger amounts (between 100 and $200 \mathrm{mg}$ ) of encapsulated particles. Production using cobalt was similar in most respects to production using nickel. The large magnetic moment of cobalt made the subsequent magnetic separation easier. Improvements such as this could lead to encapsulated particles produced by the arc method finding application in many areas, ranging from magnetic recording media to biomedical applications. ${ }^{3}$

\section{v. CONCLUSION}

Using the information gained by systematically varying the production parameters and observing their effects on the graphite encapsulated nanocrystals, a possible formation mechanism was developed. This possible formation mechanism is based on quantitative data, unlike earlier studies. ${ }^{12,15-25}$ The proposed mechanism utilizes both phase segregation and surface coating of carbon. Based on the proposed formation mechanism, the slow production rates of encapsulated magnetic particles available now can be improved upon, bringing industrial synthesis closer to reality. Notable findings included improved encapsulation when using a physically larger arc, and increased production when using a hotter arc. Additional studies can further push the boundaries of arc current production in the directions indicated by these results. Specifically, a higher arc

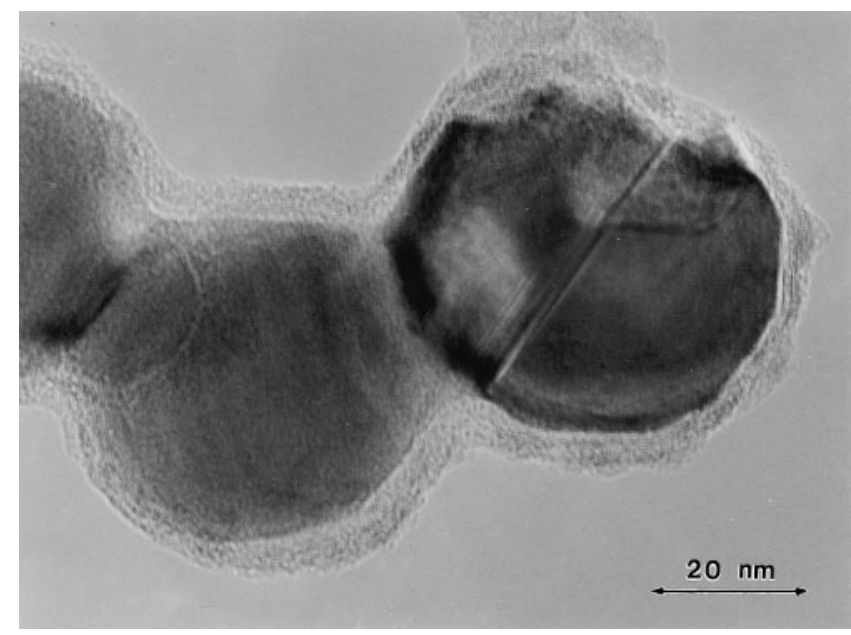

FIG. 8. HREM image of partially encapsulated particles which formed their graphite layers after crystallization. This morphology supports encapsulation of particles subsequent to crystallization, because the formation of a layer prior to crystallization (on a liquid particle) would have resulted in a single spherical particle.

current and a slightly higher carbon content may result in larger amounts of relatively pure encapsulated magnetic nanocrystals. Several areas could potentially benefit from the introduction of encapsulated magnetic particles, including the magnetic data storage field, ${ }^{4}$ biomedical diagnostic procedures, ${ }^{3}$ and others.

\section{ACKNOWLEDGMENTS}

This work was supported by the National Science Foundation NYI program, Grant DMR-9357513, with matching support from the Exxon Education Foundation. Professor D.L. Johnson, Brian Elliott, Mary Cheang, and Mark Lowe provided invaluable help in both the execution of this study and the interpretation of the results.

\section{REFERENCES}

1. Y. Yosida, Appl. Phys. Lett. 62, 3447 (1993).

2. Y. Saito, T. Yoshikawa, M. Okuda, M. Fujimoto, K. Sumiyama, K. Suzuki, A. Kasuya, and Y. Nishina, J. Phys. Chem. Solids 54, 1849 (1993)

3. M.E. McHenry, S.A. Majetich, J. O. Artman, M. DeGraef, and S. W. Staley, Phys. Rev. B 49, 11358 (1994).

4. S. A. Majetich, J. O. Artman, M.E. McHenry, N. T. Nuhfer, and S. W. Staley, Phys. Rev. B 48, 16845 (1993).

5. Y. Murakami, T. Shibata, K. Okuyama, T. Arai, H. Suematsu, and Y. Yoshida, J. Phys. Chem. Solids 54, 1861-1870 (1993).

6. E. M. Brunsman, R. Sutton, E. Bortz, S. Kirkpatrick, K. Midelfort, J. Williams, P. Smith, M.E. McHenry, S. A. Majetich, J. O. Artman, M. De Graef, and S. W. Staley, J. Appl. Phys. 75, 5882 (1994).

7. Y. Saito, T. Yoshikawa, M. Okuda, N. Fujimoto, S. Yamamuro, K. Wakoh, K. Sumiyama, K. Suzuki, and A. Kasuya, J. Appl. Phys. 75, 134 (1994). 
8. V.P. Dravid, J. J. Host, M.H. Teng, B. R. Elliott, J-H. Hwang, D. L. Johnson, T. O. Mason, and J. R. Weertman, Nature (London) 374, 602 (1995).

9. X. Lin, X. K. Wang, V.P. Dravid, R.P.H. Chang, and J. B. Ketterson, Appl. Phys. Lett. 64, 181 (1994).

10. S. A. Majetich, J.H. Scott, E.M. Brunsman, S. Kirkpatrick, M. E. McHenry, and D. C. Winkler, ECS Proceedings-Fullerenes: Physics, Chemistry, and New Directions VII (1995).

11. M.E. McHenry, E.M. Brunsman, and S. A. Majetich, unpublished.

12. S. Seraphin, S. Wang, D. Zhou, and J. Jiao, Chem. Phys. Lett. 228, 506 (1995).

13. J. J. Host, M. H. Teng, B. R. Elliott, J. Hwang, T. O. Mason, D. L. Johnson, J. R. Weertman, and V.P. Dravid, J. Mater. Res. 12, 1-6 (1997).

14. J. Host, Ph.D. Dissertation, Northwestern University (June 1997).

15. B. R. Elliott, J. J. Host, V.P. Dravid, M.H. Teng, and D. L. Johnson, unpublished.

16. C. Guerret-Piecourt, L. LeBouar, A. Lolseau, and H. Pascard, Nature (London) 372, 761 (1994).

17. S. A. Majetich, J.H. Scott, and M.E. McHenry, in Science and Technology of Fullerene Materials, edited by P. Bernier, D.S. Bethune, L. Y. Chiang, T. W. Ebbesen, R. M. Metzger, and J. W. Mintmire (Mater. Res. Soc. Symp. Proc. 359, Pittsburgh, PA, 1995), p. 29.

18. Y. Saito, T. Yoshikawa, M. Okuda, M. Ohkohchi, Y. Ando, A. Kasuya, and Y. Nishina, Chem. Phys. Lett. 209, 72 (1993).

19. Y. Saito, M. Okuda, N. Fujimoto, T. Yoshikawa, M. Tomita, and T. Hayashi, Jpn. J. Appl. Phys. 33, L526 (1994).

20. Y. Saito, M. Okuda, N. Fujimoto, and T. Yoshikawa, J. Phys. Chem. 98, 6696 (1994).

21. Y. Saito, T. Yoshikawa, M. Okuda, N. Fujimoto, S. Yamamuro, K. Wakoh, K. Sumiyama, K. Suzuki, A. Kasuya, and Y. Nishina, Chem. Phys. Lett. 212, 379 (1993).

22. S. Seraphin, D. Zhou, and J. Jiao, J. Appl. Phys. 80, 2097 (1996).

23. S. Seraphin, J. Electrochem. Soc. 142, 290 (1995).
24. S. Seraphin, D. Zhou, J. Jiao, M. Minke, and S. Wang, Chem. Phys. Lett. 217, 191 (1994).

25. S. Subramoney, Proceedings of the Symposium on Recent Advances in the Chemistry and Physics of Fullerenes and Related Materials, edited by K.M. Kadish and R.S. Ruoff, 185th Meeting of the Electrochemical Society, May 23-27 (1994), pp. $1414-1418$.

26. V.P. Dravid, M. H. Teng, J-J. Host, B. R. Elliott, D. L. Johnson, T. O. Mason, J.R. Weertman, and J-H. Hwang, United States Patent Office; Vol. 5,472,749 (Northwestern University, USA, 1995).

27. W. Krätschmer, L. D. Lamb, K. Fostiropoulos, and D. R. Huffman, Nature (London) 347, 354 (1990).

28. M. H. Teng, J. J. Host, J-H. Hwang, B. R. Elliott, J. R. Weertman, T. O. Mason, V.P. Dravid, and D. L. Johnson, J. Mater. Res. 10, 1 (1995)

29. S. Iijima, T. Ichihashi, and Y. Ando, Nature (London) 356, 776 (1992).

30. S. Seraphin, D. Zhou, and J. Jiao, Carbon 31, 1212 (1993).

31. H. Haller, Haller and Co., Cleveland, OH (1992).

32. D. Zhou, S. Seraphin, and S. Wang, Appl. Phys. Lett. 65, 1593 (1994).

33. Unpublished research on the production of unencapsulated nanocrystals by arc evaporation conducted between February '95 and April '95 by D. L. Johnson, B. R. Elliott, J. J. Host, and V.P. Dravid at Northwestern University, Evanston, IL.

34. R. E. Honig and D. A. Kramer, RCA Review 30, 285-305 (1969).

35. Phase Diagrams of Binary Nickel Alloys (1991).

36. S. Subramoney, P. Van Kavelaar, R. Ruoff, D. Lorents, and A. Kazmer, Proceedings of the Symposium on Recent Advances in the Chemistry and Physics of Fullerenes and Related Materials, edited by K. M. Kadish and R. S. Ruoff, 185th Meeting of the Electrochemical Society, May 23-27 (1994).

37. Y. Saito, M. Okuda, T. Yoshikawa, S. Bandow, S. Yamamuro, K. Wakoh, K. Sumiyama, and K. Suzuki, Jpn. J. Appl. Phys. 33, L186-89 (1994). 